\title{
EVALUATION OF THORACIC KYPHOSIS AND LUMBAR LORDOSIS AMONG VDT WORKERS AND KITCHEN WORKERS
}

\author{
V. VIJAYA LAKSHMI ${ }^{1}$, J. DEEPIKA $^{2} \&$ S. LOGESWARI ${ }^{3}$ \\ ${ }^{I}$ Principal Scientist, AICRP-H. Sc., Professor Jayashankar Telangana State Agricultural University, Hyderabad, India \\ ${ }^{2} S R F$, AICRP-H. Sc., PJTSAU, Hyderabad, India \\ ${ }^{3}$ Research Scholar, Department of RMCS, C. H. Sc., Hyderabad, India
}

\begin{abstract}
Kyphosis and Lordosis are the outward and inward curvatures of thoracic and lumbar regions of the human spine. Symptoms may include back pain, muscle fatigue, and stiffness in the back; may increase the risk of disk degeneration and injury to spinal ligaments which would affect the basic activities of daily living. In this study, 30 women were selected comprising of ten kitchen workers, 20 VDT workers inclusive of teachers and students who were above 20 years of age and using desktops and laptops for their regular work. Height in upright position with an anthropometric scale and the weight of all workers by using a weighing machine was recorded. Teachers were found to have highest mean

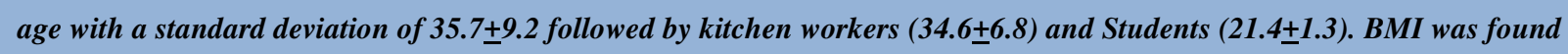
to be highest in teachers $(26.3 \pm 3.5)$ and normal BMI was found in students $(21.02 \pm 1.9)$ and kitchen workers $(23.6 \pm 5.1)$. When the degree of kyphosis and lordosis was compared by age, highest mean was found in the age group of 33-45 years. The kyposis and lordosis index when compared among VDT workers and kitchen workers, it was found to be higher in kitchen workers due to their strenuous activities. This followed by teachers with a higher range of kyposis and lordosis shown their prolonged sitting posture at work being the causative factor.
\end{abstract}

KEYWORDS: kyposis and lordosis, workers, weight \& BMI

Received: Aug 11, 2017; Accepted: Aug 31, 2017; Published: Oct 14, 2017; Paper Id.: IJESROCT201714

\section{INTRODUCTION}

Thoracic kyphosis and lumbar lordosis are the most common ones among the several postural alterations. An awkward postural position is not only visually unpleasant, but also has an impact on muscle performance and also causes the individual to be susceptible to musculoskeletal abnormalities and neural disorders. If the body continues to be in an unfavorable position for long periods of time, some muscles remain in their elongated positions while others in their contracted positions, a condition to which the individual adapts and in which contracted muscles form knots and weakness forms in elongated muscles.

It is also clear that excessive use of a particular group of muscles in a limited domain of movement leads to muscular imbalance and causes un-favorable postural changes (Herbert, 1993; Janda, 1993). Such unfavorable changes include abnormalities in thoracic and lumbar areas (kyphosis and lordosis).

Kyphosis and lordosis refer to thoracic and lumbar curves of the spinal column respectively (Rajabi and Samadi, 2008). Kyphosis is defined as an outward curvature of the thoracic spine (upper back) and lordosis is defined as an inward curvature of the lumbar (Medical systems: A Body systems approach, 2005). Kyphosis is due to the poor postures and weakened muscles, increase of which may lead to pain and risk of dysfunction in shoulder, 
pelvic girdle and spine. Symptoms may include back pain, muscle fatigue, and stiffness in the back, which would affect the basic activities of daily living. While increased lordosis may increase the risk of disk degeneration and injury to spinal ligaments.

One of the oldest and most popular non-invasive methods for the measurement of spinal curve is the Flexi ruler / Flexi curve. For the present study, $60 \mathrm{~cm}$ strip of lead covered with plastic curve was used, which can be bent in one plane only and retains the shape into which it is bent. The sample included three categories, i.e. mess workers, postgraduate students and teaching staff who is indulged in different activities like arduous household work, most of the time sitting in front of computer in awkward posture to perform the task at home and institutions. Adoption of awkward posture in the workplace may be the cause of muscle fatigue among women workers.

\section{REVIEW OF LITERATURE}

Tizabi et al., (2012) had conducted a study on thoracic and lumbar curvature among boys. They had correlated the height, weight, BMI with the kyphosis and lordosis. Boys belonged to an age group of 12-17 yrs old. Flexicurve was used to measure the sagittal curves. There was a significant correlation found to be existing between independent variables (height and weight) and dependant variables (kyphosis and lordosis).

Vakili et al., (2016) had investigated the prevalence of common postural disorders among academic dental staff of Tehran university. Forward head posture and rounded shoulder postures were the major problems found among the participants. The study has revealed that hyper lordosis seemed to be more as weight increases and was found to be significant. Forward head posture and scoliosis were significantly correlated with gender.

Teixeira and Carvalho (2007) had done a comparative study of using Cobb's method and flexicurve method for measuring thoracic kyphosis. There was a high intra class correlation coefficient (0.906) existed between the two methods. The study revealed that flexicurve method seemed to be more suitable methods than that of Cobb's method for measuring kyphosis.

Thoracic kyphosis among older female members suffering with osteoporosis was measured by using flexicurve by Teri et al (2000). The sample was subjected to 12 week exercise program and kyphosis readings were taken before and after the set time of exercise. Intra class correlation coefficients were established between kyphosis height and indices of kyphosis which was found to be highly reliable. The findings were compared with Teixeira and Carvalho study proving that flexicurve method was easy, inexpensive and reliable to measure kyphosis.

A study conducted by Eva et al., (2013) had determined the reliability of using flexicurve and inclinometer to measure thoracic kyphosis among swimmers. It was concluded that both the tools are equally reliable in measuring the kyphosis.

Taweetanalarp and Purepong (2015) had conducted a study in 18-25 years age group by using a flexicurve and the tangent method angle calculation. The results of the study revealed that there was a significant association existed between body mass index and lower lumbar angle which implied that as body weight increases, the lower lumbar angle would be deviated more leading to lordosis. 


\section{METHODOLOGY}

In this study, 30 women were selected comprising of ten kitchen workers, 20 VDT workers inclusive of teachers and students who were above 20 years of age and using desktops and laptops for their regular work. Height in upright position with an anthropometric scale and the weight of all workers by using a weighing machine was recorded. Based on the height and weight, their body mass index was calculated by using the formula $\left(\mathrm{BMI}=\right.$ weight $(\mathrm{kg}) / \mathrm{height}\left(\mathrm{m}^{2}\right)$ ).

Flexicurve was used to measure spinal curvature i.e. kyphosis and lordosis among the selected sample. Measurements were taken for the sample in standing posture by placing flexicurve on the mid line of the spine from T1, T12 and T12 to S2 vertebrae. Flexicurve was bent as per the shape of upper and lower curvature, markings were done by placing the measured flexicurve on the paper and thoracic length and width; lumbar length and width were calculated by using a ruler. After transferring the shape of flexicurve on to the paper, it was straightened and three readings were taken for each sample in the same manner.

Index of Kyphosis (IK) was calculated as a ratio of the thoracic width (TW) which is the horizontal distance from the straight line to the peak point of thoracic curvature and the thoracic length (TL) which is the vertical distance from C7 to the beginning of the lumbar curve. Thus Index of Kyphosis $(\mathrm{IK})=(\mathrm{TW} / \mathrm{TL} \times 100)$ was calculated.

Similarly Index of Lordosis (IL) was calculated as a ratio of the Lumbar width (LW) and the Lumbar length (LL) by using the formula $(\mathrm{IL})=(\mathrm{LW} / \mathrm{LL} \times 100)$. $\mathrm{LW}$ was the horizontal distance in the sagittal plane of the straight line to the point of the greatest lumbar curvature. LL was the vertical distance from the C9 marker to the point at which the curvature changed from a lumbar to pelvis region.

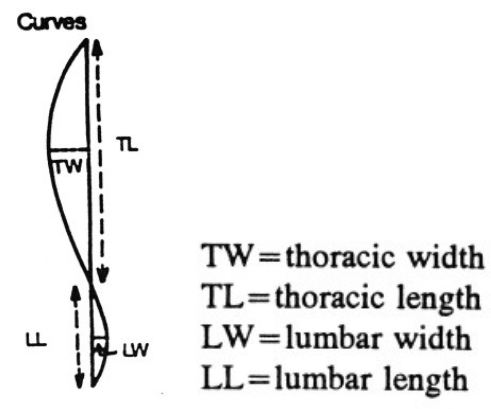

\section{RESULTS AND DISCUSSIONS}

A total of 30 women i.e. ten kitchen workers, 10 students and 10 teachers involved in different activities were selected for the study. Basic anthropometric data were collected using the standard

Equipment for the study, Among the three categories, teachers were found to have highest mean age with a standard deviation of $35.7 \pm 9.2$ followed by kitchen workers $(34.6 \pm 6.8)$ and students $(21.4 \pm 1.3)$. BMI was found to be highest in teachers $(26.3 \pm 3.5)$ and the lowest was found in students $(21.02 \pm 1.9)$. Since students were performing regular activities in the classes and the kitchen workers spend more time in strenuous mess activities, they found to have normal BMI.

Table 1: Anthropometric Data of the Respondents (MEAN + SD)

\begin{tabular}{|l|c|c|c|c|}
\hline $\begin{array}{c}\text { No of } \\
\text { Respondents }\end{array}$ & $\begin{array}{c}\text { Age } \\
(\text { Years })\end{array}$ & $\begin{array}{c}\text { Body Mass } \\
(\mathbf{K g})\end{array}$ & Height $\left.\mathbf{( M}^{\mathbf{2}}\right)$ & BMI $\left(\mathbf{K g} / \mathbf{M}^{\mathbf{2}}\right)$ \\
\hline Total $(\mathrm{n}=30)$ & $30.5 \pm \underline{9})$ & $58.06+9.6$ & $2.46+0.18$ & $23.7 \pm 4.2$ \\
\hline
\end{tabular}




\begin{tabular}{|l|c|c|c|c|}
\hline \multicolumn{5}{|c|}{ Table 1: contd., } \\
\hline $\begin{array}{l}\text { Kitchen workers } \\
(\mathrm{n}=10)\end{array}$ & $34.6 \pm 6.8$ & $58 \pm 11.8$ & $2.46 \pm 0.1$ & $23.6 \pm 5.1$ \\
\hline Students $(\mathrm{n}=10)$ & $21.4 \pm 1.3$ & $53.9 \pm 6.6$ & $2.56 \pm 0.2$ & $21.02 \pm 1.9$ \\
\hline Teachers $(\mathrm{n}=10)$ & $35.7 \pm 9.2$ & $62.3 \pm 8.9$ & $2.36 \pm 0.1$ & $26.3 \pm 3.5$ \\
\hline
\end{tabular}

Table 2: Degree of Kyphosis by Age N=30

\begin{tabular}{|l|c|c|c|c|c|}
\hline \multirow{2}{*}{\multicolumn{1}{c|}{ Age In Years }} & \multirow{2}{*}{ Number } & \multicolumn{4}{|c|}{ Kyphosis Index } \\
\cline { 3 - 6 } & & Mean & SD & Minimum & Maximum \\
\hline Below 32 years & 17 & 8.71 & 1.69 & 6.62 & 13.7 \\
\hline Between 33-45 years & 11 & 10.30 & 2.32 & 6.03 & 15.01 \\
\hline Above 46 years & 2 & 8.28 & 1.85 & 6.96 & 9.59 \\
\hline
\end{tabular}

Table 2 revealed that when the degree of kyphosis was compared by age group, below 32 years old age group had a mean index of Kyphosis as 8.71 with a standard deviation of 1.69 followed by 10.30 with a standard deviation of 2.32 for 33-45 years age group and found 8.28 kyphosis index with a standard deviation of 1.85 for above 46 years age group. However, in all the age groups, index of kyphosis found to be higher than the standards given by Milne and Lauder (1974).

Table 3: Degree of Lordosis by Age $\mathrm{N}=30$

\begin{tabular}{|l|c|c|c|c|c|}
\hline \multirow{2}{*}{\multicolumn{1}{c|}{ Age in Years }} & \multirow{2}{*}{ Number } & \multicolumn{4}{c|}{ Lordosis Index } \\
\cline { 3 - 6 } & & Mean & SD & Minimum & Maximum \\
\hline Below 32 years & 17 & 15.51 & 5.42 & 9.64 & 30.6 \\
\hline Between 33-45 years & 11 & 18.17 & 3.76 & 11.6 & 23.8 \\
\hline Above 46 years & 2 & 10.73 & 0.02 & 10.7 & 10.8 \\
\hline
\end{tabular}

Regarding the degree of lordosis, from table 3, it was found that under 32 years age group had the mean degree of lordosis as 15.51 with a standard deviation of 5.42 followed by age group between 33-45 years had 18.17 with a standard deviation of 3.76 and above 46 years age group found to have 10.73 with a standard deviation of 0.02 .

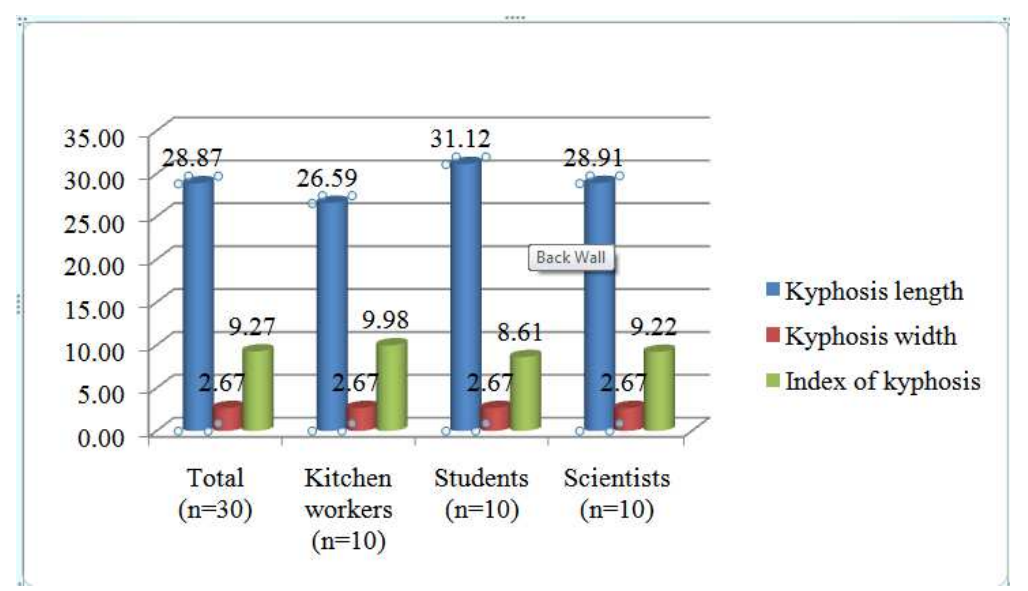

Figure 1: Mean Distribution of Kyphosis

From Figure 1, it was observed that out of 30 women, students found to be with highest mean value (31.12) regarding thoracic kyphosis length, followed by teachers (28.91) and kitchen workers (26.59) whereas the mean value of kyphosis width was found to be same in thoracic area for all.

Index of kyphosis or increased forward posture was found to be highest in kitchen workers (9.98) followed by teachers (9.22) and students (8.61). More kyphosis among kitchen workers might be due to the involvement in more 
physical work with incorrect postures. Followed by the kitchen workers, teachers were also found to have higher kyphosis which was due to their prolonged sitting posture at work involving increased usage of VDT. Though students also use VDT often for their work, they are young and not affected more by kyphosis while comparing with teachers and kitchen workers.

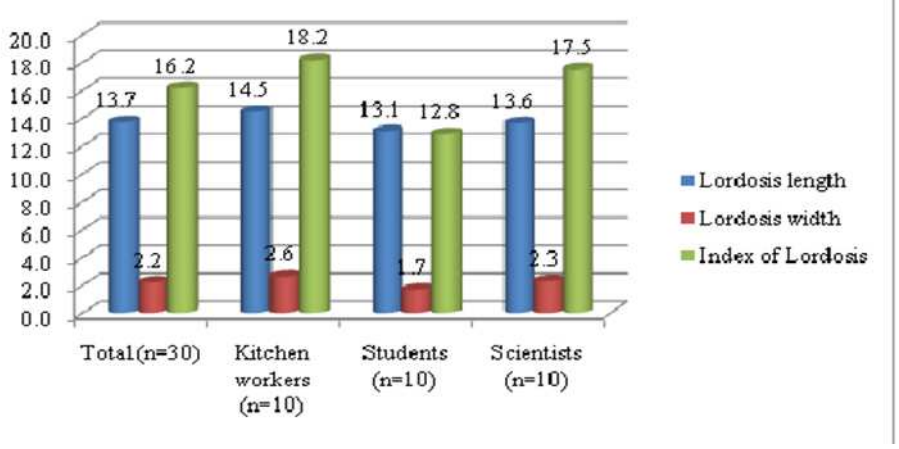

Figure 2: Mean Distribution of Lordosis

In Figure. 2, overall mean distribution of lumbar lordosis was found to be 16.2 with a lordosis length as 13.7 and lordosis width as 2.2 .

Mean value of lordosis length and lordosis width found to be higher in kitchen workers (14.5) and lower in students (13.1). This showed that kitchen workers perform activities with excess load in their lower back region leading to variation in lordosis length and width.

Table 4: Distribution of Sample on Index of Kyphosis and Lordosis

\begin{tabular}{|l|c|c|c|c|}
\hline & Mean & S. D & Min & Max \\
\hline Index of Kyphosis & 9.27 & 2.1 & 6.04 & 15.02 \\
\hline Index of Lordosis & 16.17 & 5.0 & 9.65 & 30.63 \\
\hline
\end{tabular}

When Index of kyphosis and lordosis was compared, the results revealed that the Index of lordosis or inward curve was found to have higher mean value of 16.17 with a standard deviation of 5.0 whereas Index of kyphosis was found to be 9.27 with a standard deviation of 2.1 (Table 4). This showed that the most affected region among the study group was the lumbar (lower back) region than the thoracic and cervical spine.

Table 5: Correlation between BMI with Index of Kyphosis and Index of Lordosis (N=30)

\begin{tabular}{|l|c|c|c|}
\hline & BMI & Index of Kyphosis & Index of Lordosis \\
\hline BMI & 1 & $0.206^{\mathrm{NS}}$ & $0.264^{\mathrm{NS}}$ \\
\hline Index of Kyphosis & & 1 & $0.124^{\mathrm{NS}}$ \\
\hline Index of Lordosis & & & 1 \\
\hline
\end{tabular}

When BMI was correlated with the index of kyphosis and lordosis, it was found to be nonsignificant which implies that inward curve or outward curve of the body is not related to the weight and height. It might be due to the wrong postures adopted in the work irrespective of BMI of the worker. 
Table 6: Correlation between Age with Index of Kyphosis and Index of Lordosis (N=30)

\begin{tabular}{|l|c|c|c|}
\hline & Age & Index of Kyphosis & Index of Lordosis \\
\hline Age & 1 & $0.208^{\mathrm{NS}}$ & $0.138^{\mathrm{NS}}$ \\
\hline Index of kyphosis & & 1 & $0.124^{\mathrm{NS}}$ \\
\hline Index of Lordosis & & & 1 \\
\hline
\end{tabular}

There was a non-significant relation found to be existed between indices of kyphosis and lordosis with age (Table 6). Hence it can be interpreted that age does not have any relation with the increase in kyphosis and lordosis, might be due to their health problems, working postures etc. which could be explored further.

\section{CONCLUSIONS}

From the above study, it can be concluded that among the three categories, teachers were found to have highest mean age with a standard deviation of $35.7 \pm 9.2$ followed by kitchen workers $(34.6 \pm 6.8)$ and Students $(21.4 \pm 1.3)$. BMI was found to be highest in teachers $(26.3 \pm 3.5)$ and normal BMI was found in students $(21.02 \pm 1.9)$ and kitchen workers (23.6 \pm 5.1$)$. When the degree of kyphosis and lordosis was compared by age, highest mean was found in the age group of 33-45 years. The kyposis and lordosis index when compared among VDT workers and kitchen workers, it was found to be higher in kitchen workers due to their strenuous activities. This followed by teachers with a higher range of kyposis and lordosis shown their prolonged sitting posture at work being the causative factor. Lumbar (lower back) curve region was affected more than the cervical and thoracic curve. It implies that poor and awkward postures would accentuate the variation in kyphosis and lordosis curve.

\section{REFERENCE}

1. Deepali, C. 2015. Impact of age and gender on postural stress of dairy workers. African journal of agricultural research. 10(5): 384-393.

2. Eva, B., Karen, C and Jeremy, L. Intrarater and Interrater reliability of the Flexicurve Index, Flexicurve Angle and Manual Inclinometer for the measurement of Thoracic kyphosis. Rehabilitation Research and Practice. 1-7.

3. Herbert, R. 1993. Preventing and treating stiff joints. Key issues in musculoskeletal physiotherapy. 114-141.

4. Hoseinifar, M., F. Ghiasi and A. Akbari, 2007. The Relationship between Lumbar and Thoracic Curves with Body Mass Index and Low Back Pain in Sagittal profiles of the spine. Students of Zahedan University of Medical Sciences. Journal of Medical Sciences. 7(6): 984-990.

5. Janda, V. 1993. Muscle strength in relation to muscle length, pain and muscle imbalance. Muscle strength. 83-91.

6. Milne JS, Lauder IJ, 1974. Age Effects in Kyphosis and Lordosis. Annals of Human Biology. 1:327-337

7. Rajabi, R and Samadi, H. 2008. Corrective exercise laboratory guideline. Tehran university publication institute. First edition. Tehran (Persian)

8. Taweetanalarp, S and Purepong, N. 2015. Comparision of lumbar spinal angle between normal body mass index and overweight young adults. Journal of physical therapy science. 27(7): 2343-2346.

9. Teixeira, F. A and Carvalho, G. A. 2007. Reliability and validity of thoracic kyphosis measurements using the flexicurve method. Revista brasileria de Fisioterapia. 11(3): 173-177.

10. Teri, L. Y., Murray, E. M., Keith, B., Liz, Y and David, H. 2000. Assessment of Thoracic kyphosis using the flexicurve for 
individuals with osteoporosis. Hong kong physiotherapy journal. 18(2): 53-57.

11. Tizabi, A. A. T., Mahdavinejad, R., Azizi, A., Jafarnejadgero, T and Sanjari, M. 2012. Correlation between height, weight, BMI with standing thoracic and lumbar curvature in growth ages. World journal of sport sciences. 7(1): 54-56.

12. http://dx. doi. org/10.1155/2013/475870 
